\title{
A pobreza da pobreza do Banco Mundial: influência neoliberal e determinação nos países em desenvolvimento
}

\section{The poverty of poverty of the World Bank: neoliberal influence and determination in developing countries}

\section{Silvio Aparecido Redon \\ Eliane Christine Santos de Campos*}

\begin{abstract}
Resumo: a pobreza se coloca como uma condição ineliminável na sociedade regida pelo capital, sendo o elo mais débil na relação com a riqueza, seu par dialético. Para além de sua produção, centrada na estrutura da sociedade (em uma abordagem de cariz marxiano), e da sua representação nas condições objetivas de vida da maioria da população mundial, a pobreza é alvo de investidas políticas para seu alívio, bem como de teorizações burguesas acerca de sua origem e vigência, todas descoladas da realidade social. Esse artigo visa analisar a concepção de pobreza do Banco Mundial ao longo das décadas, considerando seu papel centralizador e irradiador de medidas para seu enfrentamento nos países em desenvolvimento, pontuando sua forte presença política nessas localidades. Nos valemos de revisão de literatura sobre o tema pertinente e também da pesquisa documental, tendo como fonte principal os Relatórios do Banco Mundial, o estudo evidenciou a influência neoliberal na referida instituição e, portanto, sua importância e funcionalidade sobre o tema para a ordem burguesa.
\end{abstract}

Palavras-chave: Instituições financeiras intencionais. Economias dependentes.

\begin{abstract}
: the poverty is an inescapable condition in a society ruled by capital, being the weakest link in the relationship with wealth, its dialectical pair. In addition to its production, centered on the structure of society (in a Marxian approach), and its representation in the objective living conditions of the majority of the world population, poverty is the target of political efforts to alleviate it, as well as theorizations bourgeois about their origin and validity, all detached from social reality. This article aims to analyze the World Bank's
\end{abstract}

\footnotetext{
* Doutorando em Serviço Social e Política Social na Universidade Estadual de Londrina (UEL). Mestre em Serviço Social e Política Social ( UEL) e Graduado em Serviço Social (UEL). E-mail: silvioredonks@hotmail.com.

** Doutora em Serviço Social pela PUC-SP. Professora do Departamento de Serviço Social da Universidade Estadual de Londrina, atuando na graduação e pós-graduação. E-mail: elianecampos@uel.br.
} 
conception of poverty over the decades, considering its centralizing and radiating role of measures to confront it in developing countries, highlighting its strong political presence in these locations. We made use of a literature review on the relevant topic and also of documentary research, having as main source the World Bank Reports, the study evidenced the neoliberal influence in the referred institution and, therefore, its importance and functionality on the topic for the bourgeois order.

Key-words: International financial institutions. Dependent economies.

Recebido em 25/03/2020. Aceito em 23/07/2021

\section{Introdução}

A partir da perspectiva teórica desenvolvida por K. Marx (1982; 1984), que pressupõe a leitura da realidade social a partir da totalidade, considerando seu movimento e contradições, a pobreza é inerente ao capitalismo, cuja produção, a da pobreza, se eleva tanto mais se desenvolve a potencialidade do capital em gerar riquezas. Mas, historicamente, a pobreza é motivo de várias pesquisas e debates, o que lhe confere ser uma categoria alvo de diferentes perspectivas teóricas. Assim, a pobreza não encontra uma definição única, sendo esta variável a partir de seu embasamento teórico. Outro fator que lhe confere esse caráter incerto é seu teor político, que delimita certos aspectos normativos para estabelecer quem são e onde estão os pobres e o quanto de serviços e benefícios lhes devem ser direcionados em determinado momento histórico.

O objetivo desse artigo é explanar a concepção de pobreza do Banco Mundial (BM) que justifique as medidas impostas aos países em desenvolvimento para o alívio à pobreza. O Banco, que mantém uma relação hierarquizada com esses países, vai alterando seu entendimento sobre pobreza ao longo dos anos, assim como também se modificam as medidas de enfrentamento que lhe são pertinentes. Essa discussão se coloca importante devido ao fato de essa instituição direcionar os investimentos e medidas que devem ser adotadas pelos países tidos como periféricos no quadro da economia mundial. Assim, o artigo se valeu de revisão bibliográfica acerca da temática da pobreza e também da pesquisa documental, particularizada nos Relatórios oficiais produzidos e divulgados pelo Banco Mundial, dentre os quais o tema pobreza foi central, sofrendo significativos redimensionamentos ao longo das décadas até o presente momento.

O artigo se divide em duas sessões: a primeira, A interface entre o neoliberalismo e o Banco Mundial: incidência na pobreza, tem por primazia evidenciar que o Banco Mundial não se constitui como uma instituição livre de influências políticas e que os princípios neoliberais se fazem presente em seu interior. A segunda parte, O Banco, o desenvolvimento e a pobreza: diferentes concepções e ações, apresenta a instituição Banco Mundial, discorre sobre suas concepções de pobreza e medidas para seu enfrentamento, que vão se alterando ao longo dos anos, considerando o desenvolvimento econômico e a condição dos países de economias dependentes, os quais o BM tem grande poder de direcionamento político, social e econômico, seguidos das considerações finais. 


\section{A interface entre o neoliberalismo e o Banco Mundial: incidência na pobreza}

Para iniciarmos a proposta do presente artigo, dois pontos merecem ser destacados: a compreensão de pobreza a partir do viés neoliberal e a influência dessa ideologia que incide sobre o Banco Mundial. Assim, nos remetendo às transformações características do neoliberalismo a partir da década de 1980, como um conjunto de medidas orientadas a deter a crise econômica que se deflagrara no decênio precedente, não poderíamos nos conformar com outro entendimento: como o sucesso é algo priorizado e alcançado de forma individual, em que a intervenção do Estado corrói essa possibilidade quando interfere nas liberdades pessoais, o fracasso diante desse cenário, expresso pela pobreza, é também responsabilidade do indivíduo.

Segundo Siqueira (2013), Hayek ${ }^{1}$ reconhece que em um regime de concorrência as oportunidades dos pobres são restritas perante os ricos, mas advoga que a liberdade do indivíduo é maior nesse caso do que se comparada à de uma pessoa com maior acesso a recursos, mas vivendo em uma sociedade diferente, com menos liberdade ${ }^{2}$.

No regime de concorrência, as probabilidades do homem pobre conquistar grande fortuna são muito menores que as daquele que herdou sua riqueza. Nele, porém, tal coisa é possível, visto ser o sistema de concorrência o único em que o enriquecimento depende exclusivamente do indivíduo e não do favor dos poderosos, e em que ninguém pode impedir que alguém alcance esse resultado (SIQUEIRA, 2013, p. 70).

A pobreza se originaria dessa dinâmica competitiva, em que os melhores e mais preparados teriam vantagens sobre os menos qualificados. Vejam que, além da condenação das medidas de políticas sociais universais e consolidadas, não entendidas enquanto direito, já que teriam uma configuração de outorga, de concessão das elites, a desigualdade não é abordada enquanto estrutural e própria do sistema capitalista, em que alguns se posicionam no mercado como donos dos meios de produção e outros, diametralmente, como donos da força de trabalho, o que já traz em si o fator da necessidade de venda desse bem para a sobrevivência.

Ao contrário do que foi estruturado no Estado de Bem-estar Social europeu, em que as políticas sociais eram referenciadas no trabalho, Leher (2010) aponta que os neoliberais defendem que não é possível regular o trabalho e que o desemprego é algo natural. Mas pessoas que não estão inseridas no mercado de trabalho não podem simplesmente serem deixadas ao puro acaso; portanto, é admitida certa interferência estatal na assistência social. Esses sujeitos, em condição de miséria e passando fome e todo tipo de privação, são considerados, no discurso de Hayek, como perdedores. Nem sempre por falta de qualificação ou predicados, mas porque deram azar. Mas continuam sendo perdedores.

Hayek caracteriza essas pessoas como pobres e não como desempregadas [...]. O problema são os pobres e não os desempregados. O que fazer com os pobres:

\footnotetext{
${ }^{1}$ Hayek é autor do livro o Caminho da Servidão, escrito em 1944 e que, segundo Anderson (1995, p. 9) é o "texto de origem" do neoliberalismo. Foi também o responsável por convocar a reunião em Mont Pèlerin, na Suíça, de onde surgiria a Sociedade homônima ao local, composta por pensadores como Milton Friedman, Karl Popper, Lionel Robbins, Ludwig Von Mises, dentre outros.

${ }^{2}$ Essa liberdade defendida pelas liberais e que, junto com a democracia, só pode prosperar no mercado, é definida por Siqueira (2013, p. 70, grifo no original): “a liberdade para os liberaras é a liberdade negativa, considerada como formal e identificada pela ausência de impedimentos e constrangimentos, diferente da liberdade positiva caracterizada pela presença de condições para obtenção dos objetivos".
} 
Hayek dirá "existem perdedores; eles são pobres porque são perdedores e é claro que o Estado não pode ser insensível a isso”. O que fazer então? Dar bolsas... bolsas e não direito social organizado em torno do trabalho. Bolsa para aliviar o sofrimento, para aliviar a pobreza. É com base nisso que vai surgir, posteriormente, toda uma ciência social da pobreza que inclusive tem critérios de medição de níveis de pobreza com a precisão e a escala de um microscópio eletrônico. Assim, eles classificam: "aqui nós temos a faixa dos extremamente pobres... estes ganham a bolsa X". Vocês sabem do que estou falando. Bolsa, assistência e não mais seguridade social. É desta forma que são estruturadas as políticas dos anos 1980 e 1990 em diante (LEHER, 2010, p. 11).

É nesse âmbito de estruturação das políticas orientadas ao alívio da pobreza que temos a atuação do Banco Mundial como um elemento determinante. É interessante e necessário, como será exposto a seguir, entender que o Banco estrutura suas estratégias de ação de acordo com a fundamentação teórica que embasa seu entendimento sobre desenvolvimento e pobreza em determinado tempo histórico. Portanto, o conceito de pobreza do Banco Mundial reflete as formas de enfrentamento que são orientadas aos países em desenvolvimento. Com isso, sobre a atual conjuntura que se inicia a partir da década de 1980, é primordial uma questão defendida por Harvey (2008): a de que a hegemonia neoliberal contou com a presença de defensores dessas ideias em setores importantes da sociedade, exercendo notável influência:

[...] no campo da educação (nas universidades e em muitos "bancos de ideias"), nos meios de comunicação, em conselhos de administração de corporações e instituições financeiras, em instituições-chave do Estado (áreas do Tesouro, bancos centrais), bem como em instituições internacionais como o Fundo Monetário Internacional (FMI), o Banco Mundial e a Organização Mundial do Comércio (OMC), que regulam as finanças e o comércio globais (HARVEY, 2008, p. 13, grifo nosso).

O Banco Mundial não é imune a esse movimento em escala global e orquestrado pelo grande capital. Borón (1995) destaca que a organização conta com milhares de profissionais, entre economistas e cientistas sociais, trabalhando para imprimir legitimidade às pressões neoliberais exercidas sobre os governos. O Banco, em conjunto com o Fundo Monetário Internacional (FMI), cumpre as funções ideológicas de conferir ao neoliberalismo certo senso comum, o potencializando como poderoso instrumento burguês de controle social e político, além de estabelecer o capitalismo como a mais elevada forma de organização econômica da história.

\section{O Banco, o desenvolvimento e a pobreza: diferentes concepções e ações}

As organizações internacionais contemporâneas ganharam espaço após a Segunda Guerra Mundial como parte da necessidade de se forjarem mecanismos de cooperação para garantir a paz, a estabilidade econômica e política. Apesar de fazerem parte da Organização das Nações Unidas (ONU), tanto o BM como o FMI possuem autonomia, exceto a um conjunto muito específico de competências, funcionando, mediante pressão dos EUA, de forma independente. Após a fundação de uma organização internacional, esta alcança status de personalidade jurídica de Direito Internacional, adquirindo, com isso, independência dos países membros que as constituem, inclusive para se contrapor a eles. Essa capacidade de ação independente é conferida pela autonomia de vontade, que garante às instituições expressarem vontades jurídica e política próprias, limitadas apenas pelas suas atribuições específicas estabelecidas no tratado que as originaram. 
Nesse caso, existem organizações internacionais com poder e independência para constranger os Estados a assumirem determinados comportamentos que não os teriam se sob sua mira não estivessem, como são exemplos o FMI e o Banco Mundial, que têm poder para alterar a conduta de outros entes estatais e não estatais (SANTOS JÚNIOR, 2010, p. 16).

De acordo com Farias e Martins (2007), originalmente o Banco Mundial ${ }^{3}$ foi concebido como necessário perante as demandas resultantes da Segunda Grande Guerra. A priori, o Banco se voltava para a reconstrução da Europa devastada pelo confronto bélico. Com a sua criação, contemplada pelo Plano White, na Conferência de Bretton Woods, os americanos pretendiam criar uma agência especializada em oferecer empréstimos para a reconstrução das economias europeias, o que inicialmente foi contrariado, principalmente pelos ingleses, que esperavam que o socorro internacional viesse por meio de concessões financeiras; esse tipo de ajuda só viria em 1947 com o Plano Marshall, devido ao fato de a demanda exigida no processo de reconstrução ser maior do que o Banco poderia arcar. Havia também a preocupação estadunidense com a ameaça comunista no Leste, o que levou os EUA a atuarem na reconstrução dos países aliados e não aliados (SANTOS JÚNIOR, 2010).

A ideia de que o Banco Mundial funciona como um instrumento de dominação e controle operado pelo imperialismo para garantir a predominância de seus interesses na economia global não se sustenta com certa facilidade. Mas Santos Júnior (2010, p. 46) admite que os norte-americanos foram os que mais influenciaram suas decisões e direcionamentos "teórico-estratégicos", já que a capacidade de impor interesses no interior dessa organização se assenta no poder econômico, o que dificulta as nações pobres terem seus interesses contemplados. Além disso, o BM mantém, desde suas origens, estreita relação com o setor privado, visto que parte de seus recursos eram provenientes dos bancos comerciais e de créditos de Wall Street. Estados Unidos, BM e países em desenvolvimento se relacionariam de forma hierarquizada, cujo elo mais fraco são os que possuem menos poder econômico.

[...] o Banco sofre a influência das forças que com ele interagem e podem alterar a sua maneira de agir e se relacionar com os sócios e a sociedade, sendo uma das razões que tem feito com que assuma diferentes posturas ao longo do tempo, as vezes financiando, por exemplo, governos intervencionistas (desenvolvimentistas), como entre as décadas de 1950 e 1970 e outras vezes radicalizando nos preceitos liberais, como nos anos 1980 (SANTOS JÚNIOR, 2010, p. 3).

Findado seu objetivo inicial com a retomada da vida social europeia, o Banco começa a redirecionar sua atuação: "[...] com o passar das décadas, suas ações sempre entrelaçadas aos grandes investimentos financeiros, se direcionam principalmente para erradicar a pobreza nos países 'atrasados"' (FARIAS e MARTINS, 2007, p. 204). O Banco, então, amplia seu leque de ações e sua capacidade de investimento, se tornando o grande articulador, junto com os governos dos países que dependem de sua ajuda, do desenvolvimento e das políticas de combate à pobreza, além de aumentar seu domínio junto a essas nações.

\footnotetext{
${ }^{3}$ O Banco, cuja ata de homologação foi assinada em 27 de dezembro de 1945, é composto, na realidade, de cinco instituições de fomento, formando o Grupo Banco Mundial: tem-se o banco Internacional de Reconstrução e Desenvolvimento (BIRD), a instituição original fundada ainda em 1944; a Corporação Financeira Internacional (CFI), criada em 1956; a Associação Internacional de Desenvolvimento (AID ou AIF), erigida em 1960; o Centro internacional para Arbitragem de Disputas sobre Desenvolvimento (CIADI), criado no ano de 1966; e a Agência Multilateral de Garantia de Investimento (AMGI), surgida em 1988 (SANTOS JÚNIOR, 2010, p. 50).
} 
Até a década de 1940 a pobreza não era considerada uma categoria analítica, não designava um conjunto de países com as mesmas características capazes de influenciar a política internacional. Isso mudou ainda nessa década quando países da África e da Ásia conquistaram suas independências e chamaram atenção pela realidade de pobreza e subdesenvolvimento ${ }^{4}$. A partir da década de 1950, marcada pelo contexto da Guerra Fria, os EUA perceberam que sua segurança e a dos aliados não dependiam exclusivamente da reconstrução da Europa, mas também da estabilidade política e econômica dos países em desenvolvimento, momento em que o Banco, para evitar sua dissolução, já que a reconstrução da Europa, seu propósito original, estava em fase final, aumenta sua relevância internacional ao direcionar suas concepções e ações, da reconstrução do continente europeu, à assistência ao desenvolvimento e à pobreza. É nesse momento que despontam a Teoria do Desenvolvimento Econômico e a Teoria da Modernização que embasaram a política externa norte-americana e a assistência ao desenvolvimento, que poderia ser influenciado por forças exógenas através da ajuda internacional ${ }^{5}$, definida "como um fluxo de recursos técnicos e financeiros movimentado dos países desenvolvidos para as nações em desenvolvimento" (SANTOS JÚNIOR, 2010, p. 68).

Destarte, o subdesenvolvimento e a pobreza passaram a fazer parte da agenda internacional, influenciando a ação das organizações internacionais intergovernamentais como o Banco Mundial, os governos e o pensamento político. A ascensão dos países em desenvolvimento e subdesenvolvidos como uma realidade tangível e como categoria analítica forjou a promoção de teorias econômicas e sociológicas que procuravam explicar suas causas e os meios para explicar esse fenômeno (SANTOS JÚNIOR, 2010, p. 63).

Nos anos 1950, a noção de pobreza do Banco era percebida principalmente como desigualdade entre países e não na falta do necessário à manutenção de pessoas e grupos. Como o subdesenvolvimento e a pobreza eram analisados pelo PIB per capita, a política de empréstimo do Banco visava o desenvolvimento econômico como principal instrumento de combate à pobreza, por isso o investimento em infraestrutura, cujo deficit era um obstáculo à atividade econômica e à integração desses países na econômica global. A partir dos anos 1960, países de baixa renda não elegíveis pelos critérios do Banco passaram a receber empréstimos com a criação da Associação Internacional de Desenvolvimento (AID) ${ }^{6}$, com o intuito de forjar alterações políticas necessárias ao desenvolvimento. Como a solução para a pobreza estava no desenvolvimento econômico, não havia necessidades de amplas políticas sociais para correção das desigualdades e pobreza como, por exemplo, nos moldes do Estado Social europeu.

\footnotetext{
${ }^{4}$ Segundo Santos Júnior (2010, p. 61) a expressão era usada nos anos de 1950 a 1970 em referência às nações cujas economias não tinham alcançado os padrões de desenvolvimento tecnológico, econômico e social dos países industrializados da América do Norte (exceto México) e Europa.

${ }^{5}$ O primeiro programa global de ajuda externa aos países em desenvolvimento foi criado em 1949 (Ponto IV - Point Four Program of Technical Assistance to Development Nations), pelos Estados Unidos visando estender o sucesso do Plano Marshall à periferia. Esse programa estabeleceu as bases do desenvolvimentismo praticado por esses países nos pós-guerra, provendo recursos públicos para alavancar projetos governamentais direcionadas à infraestrutura necessária à industrialização (SANTOS JÚNIOR, 2010, p. 70-71).

${ }^{6}$ Agência especializada do Banco Mundial, criada em 1960. "Volta-se especialmente para a redução da pobreza, disponibilizando linhas de créditos em condições mais favoráveis que as demais instituições do Grupo. Nesse caso, a assistência direciona-se preferencialmente para os mais pobres entre os países em desenvolvimento, sendo seus recursos advindos de transferências dos lucros do BIRD, principalmente do repasse de doações dos Estados-membros mais ricos e das contribuições de alguns países em desenvolvimento" (SANTOS JÚNIOR, 2010, p. 51).
} 
Segundo Pereira (2010), se desde a década de 1950 o Banco passa a assumir centralidade em assuntos sobre desenvolvimento, em que a redução da pobreza figura como uma de suas dimensões, é na gestão de Robert S. McNamara na presidência do Banco Mundial (abril de 1968 a junho de 1981) que se opera uma verdadeira inflexão sobre o assunto e as estratégias adotadas. Como nos informa Santos Júnior (2010), um balanço sobre a ajuda internacional praticada nos últimos 20 anos e evidenciada no Relatório Pearson (conhecido também como "Sócios no Progresso" ou "Informe Pearson") evidenciou que, mesmo com o aumento das taxas de crescimento, a desigualdade aumentara e a maior parte da população dos países da periferia continuava pobre; o desenvolvimento proposto não levara a redução da pobreza.

De acordo com Santos Júnior (2010), foi a partir do Relatório Pearson que na gestão de McNamara a assistência social passou a ser entendida como parte integrante do processo de desenvolvimento, ou seja, o social e o econômico se integravam de forma complementar. É nesse momento, que os projetos ao atendimento às necessidades sociais básicas ${ }^{7}$ e alívio da pobreza passaram a ser incorporadas nas estratégias do Banco, repercutindo no aumento dos recursos para as políticas sociais.

As políticas de atendimento das necessidades básicas e alívio da pobreza foram integradas ao desenvolvimento porque as desigualdades sociais e a marginalização de amplas camadas da população criavam contratempos para a transição completa de economias atrasadas em modernas economias de mercado. Pelas teses defendidas pelo Banco Mundial na década de 1970, os pobres deveriam ser encarados como um dos principais ativos das economias em desenvolvimento e, por essa razão, não deveriam ser vistos como problema, mas como solução (SANTOS JÚNIOR, 2010, p. 146, grifo nosso).

À época, como nos esclarece Pereira (2010), a institucionalização do enfrentamento à pobreza se vincula ao estabelecimento desta enquanto categoria analítica e o envolvimento do Banco em pesquisas, produção e publicização de dados. Isso foi possível com a definição de "pobreza absoluta", entre 1972/1973, e de "pobreza relativa", no ano seguinte. Até então a pobreza figurava na literatura acadêmica de modo vago e marginal; antes da gestão McNamara se falava em "necessidades sociais", não em "pobreza”. Agora, a instituição visa o aumento da produtividade dos sujeitos para superação da pobreza, condição em que se encontravam pessoas não inseridas no circuito de atividades produtivas e rentáveis, segundo o BM. Uma proposta inteligente.

Tal proposição operava um triplo movimento: primeiro, apagava o caráter desigual e combinado das formas de exploração e, portanto, a "funcionalidade

\footnotetext{
${ }^{7}$ As necessidades básicas se caracterizam por serem universais ao homem, independente de cultura e civilização: alimentarse, tratar-se e agir. São tanto físicas como psíquicas, sendo satisfeitas por meio de uma variedade de formas econômicas. Há uma crítica sobre essa ideia, pois essa universalização deriva de uma homogeneização dos países desenvolvidos que conferiram seu conteúdo a partir de suas realidades (SALAMA e DESTREMAU, 1999, p. 75). Mas o debate sobre as necessidades básicas não é unívoco: há autores que discordam sobre quanto à sua subjetividade. Esse debate é compreendido em Pereira (2011).

${ }^{8}$ Tanto a pobreza absoluta quanto a relativa se ancoram na visão unidimensional da renda. A pobreza absoluta expressa a condição em que um indivíduo ou grupo de encontra em renda suficiente para se reproduzir: a renda é convertida ao mínimo de calorias para a reprodução fisiológica, acrescida de despesas de moradia e transporte. Quem está situado abaixo dessa linha é considerado pobre. Essa medida é usada nos países em desenvolvimento e EUA, cuja vantagem é indicar a falta de recursos, um dos aspectos para a família se reproduzir (SALAMA e DESTREMAU, 1999, p. 18 e 51).

${ }^{9}$ Também é uma medição monetária, mas se vale da distribuição dos salários para definir a pobreza e não por uma linha estabelecida. Com isso, é considerado pobre quem está abaixo de $40 \%$ e $60 \%$ do rendimento médio da população, a depender do país. As pessoas são localizadas através dos salários (SALAMA e DESTREMAU, 1999, p. 18).
} 
dos pobres" (desempregados, subempregados, pequenos agricultores etc.) para a acumulação capitalista; segundo, isolava a pobreza do conjunto das relações sociais, como se fosse um fenômeno em si mesmo; terceiro, reificava as modalidades mais predatórias de desenvolvimento capitalista, na medida em que explicava a pobreza como exclusão do progresso, e não como um dos seus resultados (PEREIRA, 2010, p. 268).

Isso revela que a estratégia do Banco, mesmo com o aumento de investimento e de entendimento sobre desenvolvimento e pobreza, não choca com princípios capitalistas de acumulação. O financiamento das políticas de alívio à pobreza só ganhou espaço depois que o BM conseguiu se desvencilhar de preceitos de equidade e redistribuição ligados ao Welfare, não contemplados nas estratégias de atendimento ao alívio da pobreza, "que deveria ser superada conforme o progresso econômico e tecnológico e as políticas sociais eram parte desse projeto, não um apêndice de última hora", segundo Santos Júnior (2010, p. 134).

A questão é que as políticas aludidas propunham um conjunto de instrumentos públicos, sociais e econômicos que intentavam garantir o essencial para a reprodução da vida e da força de trabalho. Tratava-se, pois, de uma concepção que entendia as causas estruturais da pobreza relacionada à estagnação econômica das sociedades dualistas, de modo que, para romper com essa inércia, seria preciso redimensionar o papel do Estado no processo de desenvolvimento econômico (SANTOS JÚNIOR, 2010, p. 136, grifo nosso).

Mas, de acordo com Pereira (2010), devido a conjuntura dos anos 1970 o Banco repensa suas ações. É em 1979, para fazer frente à crise desencadeada no início da década, que McNamara apresenta os programas de ajustes estruturais que privilegiam o ajuste econômico, em detrimento das políticas de atendimento às necessidades básicas e alívio da pobreza, para enquadrar os países endividados e responder à nova realidade entre Estado e mercado ditada tanto pelas exigências neoliberais, como também pela alteração na correlação de forças entre capital e trabalho.

A década de 1980 marca um quadro de crise mundial. Até meados da década de 1970 a recessão não tinha prejudicado os países em desenvolvimento (SANTOS JÚNIOR, 2010). Isso porque, segundo Pereira (2010), enquanto as economias centrais sentiam os reflexos da crise, numa combinação de inflação alta, baixo crescimento e aumento do desemprego, alguns países da periferia, como Brasil, Taiwan, México, cresciam em larga escala, mas às custas de endividamento externo devido ao acesso fácil a créditos de bancos privados no contexto de alta do preço do petróleo. Outras nações, que empobreciam ou cresciam de forma não satisfatória, também recorriam aos empréstimos no Banco.

Para Pereira (2010), em 1979 os projetos sociais passam a figurar menos ainda como medida do Banco e a bandeira de "ataque à pobreza" lentamente deixa de figurar no discurso de McNamara que, no mesmo ano, anuncia a criação do empréstimo de ajustes estruturais ${ }^{10}$ para enquadrar essas nações endividadas - cujas condições se revelaram explicitamente com a moratória mexicana em 1982 - na nova realidade da dinâmica econômica neoliberal. Com isso, "mecanismos de proteção ou compensação parcial a grupos sociais mais vulneráveis ao ajuste não foram cogitados”

\footnotetext{
10 “De desembolso rápido e orientado para políticas, e não para projetos, tinha o objetivo de financiar o deficit no balanço de pagamentos, sobretudo de países importadores de petróleo. A autorização desse tipo de empréstimo estava condicionada à realização, pelo prestatário, de um programa de estabilização acordado previamente com o FMI e de um pacote de reformas na política macroeconômica, ambos voltados para adequar a economia doméstica ao novo ambiente externo e manter o pagamento do serviço da dívida externa" (PEREIRA, 2010, P. 271).
} 
(PEREIRA, 2010, p. 272). Nesse momento, o Banco investe no abandono de práticas desenvolvimentistas das décadas anteriores, entendendo o Estado como ineficiente e o responsável por deflagrar a crise econômica internacional. Operam-se, então, os ajustes de "primeira geração" (SANTOS JÚNIOR, 2010, p. 155), quando o atendimento às necessidades básicas e alívio à pobreza são interpretadas pelo governo norte-americano como erros socialistas, deixando de terem prioridade nos empréstimos do BM em prol dos programas de ajustes estruturais. Importante é ressaltar o fato de que, nesse primeiro momento de implantação, os ajustes não contemplavam medidas de proteção ou compensação à população atingida, tanto pela crise como pelos programas; a focalização de que falam os autores deve ser entendida às ações direcionadas a quem necessitasse urgentemente de amparo para repor as condições mínimas de sobrevivência.

A imposição dos ajustes estruturais, estrategicamente arquitetados pelo BM e FMI como condição para a renegociação da dívida externa dos países em desenvolvimento (MAURIEL, 2009) e também para a liberação de novos empréstimos, se alicerça nas condicionalidades, que "ditam compromissos de natureza econômica, política e financeira” (SANTOS JÚNIOR, 2010, p. 164). Com isso, o Banco estabelece que o não comprometimento com as condicionalidades significa não acesso aos empréstimos necessários aos países em desenvolvimento; nesse jogo de interesses, as nações se subordinam ao poder das instituições.

Segundo Chossudovsky (1999, p. 11), o "movimento da economia global é regulado por um processo de cobrança de dívida em âmbito mundial, que sufoca as instituições do Estado nacional e contribui para eliminar empregos e reduzir a atividade econômica". É o endividamento desses países que tutela as nações soberanas ao poder das Instituições Financeiras Internacionais (IFIs), que as obriga a cumprirem uma série de condicionalidades que remodelam suas políticas mediante interesses dos credores oficiais e comerciais, comprometendo a soberania desses países. "Os credores só concordam com a rolagem da dívida se a nação devedora aceitar as condicionalidades políticas que fazem parte dos acordos de empréstimo" (p. 43). Essas imposições de reformas levam ao que o autor qualificou como "globalização da pobreza, processo que aniquila a subsistência humana e destrói a sociedade no Sul, no Leste e no Norte” (CHOSSUDOVSKY, 1999, p. 27).

Desde o começo dos anos 80, os programas de "estabilização macroeconômica" e de "ajuste estrutural" impostos pelo FMI e pelo Banco Mundial aos países em desenvolvimento (como condição para renegociação da dívida externa) tem levado centenas de milhões de pessoas ao empobrecimento [...]. O poder de compra interno entrou em colapso, a fome eclodiu, hospitais e escolas foram fechados, centenas de milhões de crianças viram negados seu direito à educação primária. Em várias regiões do mundo em desenvolvimento, as reformas conduziram ao ressurgimento de doenças infecciosas, entre elas a tuberculose, a malária e o cólera (CHOSSUDOVSKY, 1999, p. 26).

Segundo os estudos de Chossudovsky (1999, p. 47, grifo nosso), os ajustes neoliberais apresentam duas fases distintas: “estabilização econômica 'a curto prazo' a ser seguida pela implementação de diversas reformas estruturais mais fundamentais (e ditas 'necessárias')"11. Sob isso, sobressai-se o caráter das medidas neoliberais sobre a questão da pobreza: se a estabilização econômica requer austeridade orçamentária, a reforma estrutural traz a "diminuição da pobreza"

\footnotetext{
${ }^{11}$ A estabilização econômica implica desvalorização da moeda, liberação de preços e a estabilidade orçamentaria; as reformas estruturais envolvem medidas de liberalização do comércio, a desregulamentação do sistema bancário, a privatização de empresas estatais, a reforma fiscal, a privatização das terras cultiváveis, a "diminuição da pobreza" e ao "bom governo" (CHOSSUDOVSKY, 1999).
} 
(CHOSSUDOVSKY, 1999, p. 58) como uma condicionalidade para prevalência de acordos de empréstimos com o Banco Mundial. Impõem-se, então, a administração da pobreza pelos países com custos orçamentários mínimos, de modo que não comprometa o processo de acumulação e reprodução do capital.

A legitimação da transferência da lógica das políticas sociais para o alívio focalizado à pobreza encontrou forças ideológicas que sobrevieram dos meios acadêmicos e de pesquisa dos Estados Unidos. Mauriel (2009) aponta que a partir de um olhar sobre os Estados Unidos, é possível demonstrar que:

[...] o caminho percorrido pelas políticas sociais norte-americanas e as concepções que seguiram daí serviram de fonte de inspiração e de base para novas construções ideais sobre como promover bem-estar social, assegurando lugar central para o alívio da pobreza no debate sobre política social na atualidade (MAURIEL, 2009, p. 60).

Segundo Santos Júnior (2010), os primeiros ajustes efetivados tiveram amplas consequências negativas, como expansão do desemprego, a queda nos salários, a migração e o aumento da pobreza, principalmente nos países da América Latina e África Subsaariana. Esse questionamento da eficácia dos ajustes, como pontua o autor, foi primeiramente formulado pelo Fundo das Nações Unidas para a Infância (Unicef) e publicado em 1987 no Relatório Ajuste com Rostro Humano, apontando piora na situação dos países pobres causada pela crise econômica e a forma de ordenação dos ajustes que priorizaram o aspecto econômico e renegando o social. Reconhecendo os limites dos ajustes estruturais, o Banco Mundial incorpora novamente o combate à pobreza, sob um novo enfoque.

Assim, a partir da década de 1990, ascendem no interior do Banco as políticas de ajuste de "segunda geração" focadas notavelmente nas reformas institucionais. A constatação de que os elementos políticos influenciaram negativamente o processo de ajuste econômico dos países em desenvolvimento levaria o BIRD, doravante, a priorizar questões como governabilidade e governança, já que, em tese, os problemas políticos tinham um grande potencial para desestabilizar a economia, atrasando ainda mais o processo de desenvolvimento nos países pobres (SANTOS JÚNIOR, 2010, p. 203).

As reformas econômicas seriam bem sucedidas quando do bom funcionamento das instituições e da estabilidade política e financeira dos governos, por isso a necessidade de reforma de Estado, extensiva aos países em desenvolvimento e aos da extinta União Soviética, em que o sistema de propriedade privada não era consolidado. O Estado deveria voltar para suas atividades clássicas: segurança, de pessoas e propriedade; justiça, no tocante à leis; economia, na responsabilidade quanto à cunhagem de moeda e estabilidade financeira e econômica e; garantias sociais, assistência apenas aos mais pobres, seguridade e meio ambiente (SANTOS JÚNIOR, 2010, p. 219).

Um marco da discussão da pobreza é o Relatório Sobre o Desenvolvimento Mundial, publicado pelo Banco em 1990 que "trata da pobreza no mundo em desenvolvimento - ou seja, trata dos pobres mais pobres do mundo" (BANCO MUNDIAL, 1990, p. 1). Para Farias e Martins (2007, p. 210), é onde se concentra a influência da instituição que se preocupa em isolar a pobreza - mesmo sabendo da existência de pobres nos países ricos, isso não é evidenciado em documentos ou no site oficial do BM. O conceito de pobreza que predomina é o estabelecido pela renda per capita ${ }^{12}$,

\footnotetext{
12 "Os grupos de países adotados neste Relatório são assim definidos: Economias de baixa renda são aquelas com PNB per capita igual ou inferior a US\$545 em 1988. Economias de renda média são aquelas com PNB per capita superior a US\$545, mas
} 
sendo definido vagamente como "a incapacidade de atingir um padrão de vida mínimo" (BANCO MUNDIAL, 1990, p. 27). Portanto, a pobreza é entendida como o não acesso dos sujeitos aos bens e serviços, num aspecto estritamente econômico. Numa retomada, o Banco sintetiza as medidas adotadas em decênios precedentes na luta contra a pobreza.

Nos anos 50 e 60, muita gente considerou ser o crescimento o melhor meio de reduzir a pobreza e elevar a qualidade de vida. [...]. Nos anos 70, passou-se a atentar especificamente para prestação de serviços de saúde, nutrição e educação, vistos como questões de política pública. O Relatório sobre a desenvolvimento Mundial 1980, com base nos indícios então disponíveis, sustentou que melhorar a saúde, a educação e a nutrição dos pobres era algo não só intrinsecamente importante, mas também um meio de estimular o aumento das rendas, inclusive dos pobres (BANCO MUNDIAL, 1990, p. 1-2).

Sobre os anos 1980, o Banco apontou a necessidade dos ajustes, mas admite os efeitos colaterais das medidas e necessidade de se pensar políticas que reduzam a pobreza. A estratégia para os anos 1990 se volta para dois elementos: o trabalho, o bem que o pobre mais possui, e serviços sociais básicos, como atendimento médico, nutrição, planejamento familiar. Existindo a certeza de que muitos pobres ficam em situação de risco num curto prazo, esse processo deve ser acompanhado de políticas macroeconômicas e medidas para contrarrestar a queda do consumo dos pobres. Mas para as transferências há o imperativo de "definir com mais precisão as clientelas-alvo" (BANCO MUNDIAL, 1990, p. 3). No entender do Banco:

O primeiro componente cria oportunidades; o segundo capacita o pobre a tirar proveito dessas oportunidades. A estratégia precisa ser completada com estratégias bem seletivas, para ajudar os que não se beneficiam dessas políticas, e por esquemas de segurança, para proteger os que se acham expostos a choques (BANCO MUNDIAL, 1990, p. III, grifo nosso).

Os anos 1990 são, de acordo com Mauriel (2013) $)^{13}$, marcados pela focalização para contrabalançar os ajustes postos em práticas, com tendência de iniciativas compensatórias forjadas em um assistencialismo precário. Além disso, esses esquemas de alívio à pobreza (compreendendo aqui um menor compromisso do Banco em relação aos anos 1970) respondem ao movimento de expansão e contração da economia global, trazendo em seu bojo uma funcionalidade manipulada pelo grande capital, tese também defendida por Netto (2007) e Laurell (1997, p. 193), quando se remete a um "objetivo oculto" 14 .

inferior a US\$6.000 em 1988. Este grupo divide-se ainda em economias de renda média baixa e economias de renda média alta, a um PNB per capita de US\$2.200 em 1988. Economias de alta renda são aquelas com PNB per capita igual ou superior a US\$6.000 em 1988". (BANCO MUNDIAL, 1990, p. x).

${ }^{13}$ Mauriel $(2009 ; 2013)$ defende outra cronologia que a de Santos Júnior (2010). A autora admite transformações nas políticas de proteção social a partir dos anos 1980, tanto que cita um simpósio realizado em Helsinki realizado em 1987 , “O Banco abandonou seu foco de Alívio à Pobreza?”, que critica a atuação da organização, mas não qualifica esse período como ajustes de primeira geração, como Santos Júnior. Para Mauriel, a primeira geração de ajustes acontece em 1990 e a segunda nos anos 2000. Para Santos Júnior, a década de 1980 marca a primeira e a década posterior a segunda, que se estende nos anos 2000.

${ }^{14}$ Esse "objetivo oculto" de que fala Laurell (1997, p. 173) se refere justamente a essa funcionalidade política adquirida pelos programas de combate à pobreza na América Latina; "assegurar uma clientela política em substituição ao apoio popular baseado num pacto social amplo, impossível de se estabelecer no padrão das políticas neoliberais”. 
[Existe um] papel estratégico central que o conjunto de ações de combate à pobreza possui hoje para a manutenção do atual padrão de acumulação via financeirização, seja regulando os custos de trabalho no mercado mundial, seja por meio da regulação do comportamento econômico, político e civil dos pobres, garantindo baixo risco de sublevação social e uma forma ideologicamente palatável de inserção precária dessas massas na ordem econômico-financeira contemporânea (MAURIEL, 2009, p. 45).

O Banco age sob a perspectiva de redução da pobreza, não sua erradicação. E o faz advogando que a tática adotada não reflete grande ônus aos países industrializados. Mas essa ajuda externa depende do comprometimento dos países em adotar programas de desenvolvimento que visem a redução da pobreza, já que esta meta se consolida como "critério condicional dos acordos de empréstimos com o Banco Mundial e FMI” (MAURIEL, 2009, p. 58).

Salama e Destremau (1999, p. 40) dizem que a fixação do Banco sobre o crescimento ser um "remédio miraculoso para a pobreza" se assenta em duas proposições: o aumento do emprego e o crescimento da produtividade, e, com ela, os salários. Contudo:

Sua eficácia depende, a priori, de dois parâmetros: por um lado, a amplitude do crescimento e sua duração e, por outro, a importância da pobreza, a distância entre linha da pobreza do rendimento médio dos pobres e distribuição da pobreza entre os pobres (SALAMA e DESTREMAU, 1999, p. 41).

Mas essa evolução pode ser contida ou catalisada a depender de três fatores: o ciclo da pobreza seja longo e expressivo; a implementação de uma política de distribuição de renda e; as variações da taxa de inflação ${ }^{15}$ (SALAMA e DESTREMAU, 1999). Portanto, para o crescimento refletir sobre a pobreza de forma significativa, este deve ser contínuo e duradouro, acompanhado de políticas sociais e em meio a uma conjuntura de baixa inflação. No entanto, outro elemento característico, particularmente nas sociedades latino-americanas, não deve ser descartado, um elemento que a pobreza mantém relação estreita: a desigualdade. Esta incide sobre os níveis da primeira e aparece como um complicador da falsa tese capitalista sobre o fim de pauperismo: o crescimento. "A evolução da pobreza depende no total de três fatores: a taxa de crescimento, o nível de desigualdade e sua variação" (SALAMA, 2005, p. 190). Na explicação do autor encontramos a clareza dessa questão:

Quanto mais elevado for os níveis da desigualdade, menos o crescimento diminuirá a pobreza, se as desigualdades permanecerem constantes (crescimento neutro do ponto de vista dos efeitos distributivos). E inversamente, se as desigualdades se acentuarem, uma maior taxa de crescimento se tornará necessária para diminuir a amplitude da pobreza, mais do que se elas permanecessem estáveis (SALAMA, 2005, p. 190).

\footnotetext{
${ }^{15}$ Com dados de publicação de 1996 de Barros, Camargo e Mendonça, Salama e Destremau (1999, p. 43) dizem que apenas o crescimento não é possível de impactar sobre a pobreza de maneira significativa em um tempo razoável: "seria preciso, com efeito, esperar uns vinte anos, com taxa de crescimento constante do PIB de 3\% ao ano, para que o tamanho da pobreza no Brasil (40\% de pobres) se tornasse comparável à taxa que o país teria tido se tivesse um perfil de distribuição de renda semelhante ao da Costa Rica ( $24^{\circ}$ posição na escada de desigualdades, e 20\%de pobres)". Esses dados atestam a necessidade de manutenção e ampliação das políticas de redistribuição de renda.
} 
Assim, a desigualdade ${ }^{16}$, expressa pela distribuição e concentração desigual de renda no seio da sociedade e elementarmente potencializada na relação capital e trabalho em conjuntura neoliberal, pode contrarrestar os vetores capazes, nas condições aludidas, de incidir sobre a pobreza, implodindo a possibilidade de efetivação de realidades contrastantes a atual, como foi a excepcionalidade do Estado Social europeu, um lapso temporal de forte redução da pobreza absoluta e das desigualdades.

Em uma avaliação dez anos depois, em um novo Relatório - Relatório Sobre o Desenvolvimento Mundial 2000/2001, Luta contra a Pobreza - o Banco, timidamente, aponta alguns avanços, mas admite que a pobreza ainda figura como um problema de proporções enormes. Portanto, novamente é apresentada uma nova inflexão quanto ao seu entendimento sobre pobreza e a ofensiva para sua redução:

[...] a pobreza é mais que renda ou desenvolvimento humano inadequado; é também vulnerabilidade e falta de voz, poder e representação. Esta visão multidimensional da pobreza aumenta a complexidade das estratégias de redução da pobreza, porque é preciso levar em conta outros aspectos, como os fatores sociais e as forças culturais (BANCO MUNDIAL, 2000/2001, p. 12, grifo nosso).

A definição multidimensional de pobreza do BM se origina do estudo Vozes dos Pobres ${ }^{17}$; além da visão tradicional da pobreza, representada pela privação material e baixos níveis de saúde e educação expressos no Relatório de 1990, agora é incorporado ao conceito a vulnerabilidade ${ }^{18}$ e exposição a riscos, falta de influência e poder. As causas da pobreza se assentam nas dimensões citadas pelos pobres no referido estudo: falta de renda e recursos para as necessidades básicas; falta de poder e voz frente o Estado e a sociedade para terem suas demandas atendidas e; vulnerabilidade a diversos choques e impotência para enfrentá-los. Nesse momento são estabelecidos os Objetivos do Milênio, dentre os quais "reduzir pela metade a proporção de pessoas que vivem em extrema pobreza (menos de 1 dólar por dia)”, até 2015. (BANCO MUNDIAL, 2000/2001, p. 6).

Partindo de que a pobreza é resultado não apenas de processos econômicos, mas também políticos e sociais, embora, sem espanto, não problematize a estrutura da sociedade, o Banco (2000/2001) estabelece três novas frentes de ação: promover a oportunidade, facilitar a participação e aumentar a segurança. O que mantém as pessoas na condição de pobreza é a escassez de bens, mercados inacessíveis e poucas oportunidades de emprego. Mas o BM reforça que o desenvolvimento econômico, como em outros momentos, é fundamental para a redução da

\footnotetext{
${ }^{16}$ De fato, essa dinâmica entre desenvolvimento, desigualdade e pobreza é complexa. Dessa relação vale apontar que não se pode concluir que o aumento da desigualdade gera aumento da pobreza. Há casos em que essa relação, que num primeiro momento parece óbvia, como causa e efeito, se efetiva de forma inversa: há países em que crescem as desigualdades mas diminui a pobreza devido à alta taxa de crescimento por um período longo, realidade conhecida pelo Brasil na década de 1970 e também pela China (SALAMA e DESTREMAU, 1999, p. 31).

${ }^{17} \mathrm{O}$ estudo Vozes dos Pobres foi realizado para o Relatório de 2000/2001. Foi realizado em 60 países, com mais de 60.000 homens e mulheres pobres. "O estudo mostra que os pobres são agentes ativos em suas vidas, mas em geral não conseguem influenciar os fatores sociais e econômicos que determinam seu bem-estar" (BANCO MUNDIAL, 2000/2001, p. 3). Os pobres entendem o bem-estar como "felicidade, harmonia, paz, ausência de ansiedade e paz de espírito [...]. As pessoas descrevem mal-estar como carência de bens materiais, más experiências e sentimentos pessoais negativos" (BANCO MUNDIAL, 2000/2001, p. 16).

${ }^{18}$ O Banco (2000/2001, p. 19) define a vulnerabilidade: nas dimensões de renda e saúde, vulnerabilidade é o risco de que uma família ou um indivíduo venha a passar eventualmente por um episódio de pobreza em função de renda ou saúde. Porém, vulnerabilidade também significa a probabilidade de exposição a diversos outros riscos (violência, crime, catástrofes naturais, ser tirado da escola).
} 
pobreza. A vulnerabilidade decorreria, também, da incapacidade do Estado ou comunidade em criar meios para reduzir os riscos a que os pobres estariam expostos. Os governos são mais sensíveis aos interesses da elite enquanto os pobres não conseguem ser ouvidos pelas instituições.

De acordo com Mauriel (2013), a partir dos anos 2000, o entendimento do Banco sobre pobreza sofre influência teórico-intelectual da obra de Amartya Sen, em que o desenvolvimento passa por um processo que objetiva a expansão das liberdades das pessoas, que são exercidas desde que haja condições para essa possibilidade, como saúde e educação, garantia de participação política e oportunidades econômicas para empreenderem no mercado. Portanto, depende que os sujeitos tenham acesso à bens de valor social para seu ingresso no mercado. A pobreza atrelada ao perfil do indivíduo traz sua existência embutida à própria existência do homem, como algo inerente e insuperável. Mesmo diante desse redimensionamento:

[...] a política social do Banco continuou sendo, de fato, a política econômica. A ideia de desenvolvimento como liberdade centra-se na capacidade individual. Seja através de intitulamentos, empoderamento ou da geração de renda, o Banco não avança para um projeto de bem-estar social como direito de cidadania e redistribuição de renda e propriedade (SANTOS JÚNIOR, 2010, p. 235).

Sob uma nova perspectiva sobre a pobreza, agora atrelada a ideia de desenvolvimento, as políticas sociais são refuncionalizadas para garantir títulos/habilitações aos pobres para que estes possam ampliar suas "liberdades" pessoais e gerar suas próprias rendas, tornando-os mais competitivos e empreendedores, com mais condições de criar soluções para suas demandas econômicas e políticas. Isso legitimaria as políticas compensatórias e de alívio à pobreza ao corrigirem distorções vindas de desigualdades que fogem a escolhas e que colocariam o sujeito em desvantagem na concorrência do mercado, como ser pobre, negro ou mulher (MAURIEL, 2013, p. 108)

O Relatório Um Melhor Clima de Investimento para Todos, de 2005, traz em seu prefácio que a publicação se "trata da criação de oportunidades para que as pessoas evitem a pobreza e melhorem seus padrões de vida" (BANCO MUNDIAL, 2005, p. XIII, grifo nosso). Mantém, portanto, a situação de pobreza vinculada à individualidade, mas aborda um ponto tido como desafio para o desenvolvimento: a criação de um clima de investimentos ${ }^{19}$ para que empresas e empresários tenham oportunidades e incentivos para investir, criar empregos e crescer, contribuindo para o crescimento e a redução da pobreza. Defendendo que o crescimento econômico é o único mecanismo sustentável para o aumento do padrão de vida, o BM propõem um pensamento linear: de que os governos devem garantir boas condições de investimento ${ }^{20}$, o que repercutiria no crescimento e prosperidade; a demanda por emprego aumentaria, criando oportunidades para as pessoas aplicarem seus talentos e melhorarem sua situação. A justificativa para esse pensamento é:

A importância do clima de investimento para a redução da pobreza pode ser vista de duas formas. Primeiro, no nível agregado, o crescimento econômico está intimamente associado à redução da pobreza [...]. Segundo, a contribuição pode ser vista pela forma como um bom clima de investimento melhora

\footnotetext{
${ }^{19}$ Segundo o BM (2005, p. 22), o clima de investimento "é o conjunto de fatores locais específicos que moldam as oportunidades e incentivos para as firmas investirem produtivamente, criarem empregos e crescerem. Política e ações governamentais exercem uma forte influência graças a seu impacto sobre custos, riscos e barreiras à competição".

${ }^{20}$ Os governos devem incidir sua influência "na garantia dos direitos de propriedade, na escolha das diferentes abordagens para a regulação e tributação, na provisão de infraestrutura, no funcionamento dos mercados financeiros e de trabalho e nas questões relativas à governança, como, por exemplo, a corrupção" (BANCO MUNDIAL, 2005, p. 2).
} 
diretamente a qualidade de vida das pessoas diretamente, influindo em suas muitas capacidades (BANCO MUNDIAL, 2005, p. 3-4).

Além disso, os pobres ouvidos para o estudo Voices of the Poor, atribuíram a obtenção de trabalho como um caminho para a superação da pobreza. O clima de investimentos tem papel central para o crescimento e, consequentemente, a redução da pobreza: "Um bom clima de investimento fortalece o investimento privado - que é a alavanca para o crescimento e redução da pobreza" (BANCO MUNDIAL, 2005, p. 21).

E essa falta de trabalho desencadeia uma série de consequências, não apenas a carência material pela impossibilidade de acesso, mas de destituição social, de sua condição de membro, da fragilização e até do rompimento de seus vínculos familiares e comunitários. Contudo, Mandel (1982) aponta ser o desemprego e subemprego características dos países em desenvolvimento e que remonta à exploração europeia em épocas pré-capitalistas:

"Do ponto de vista marxista, isto é, a partir de uma teoria consistente do valor do trabalho, subdesenvolvimento é sempre, em última análise, subemprego, quantitativamente (desemprego em massa) e qualitativamente (baixa produtividade do trabalho)" (MANDEL, 1982, p. 40, grifo no original).

O Relatório de 2005 ainda ressalta que o combate à pobreza também deve considerar o investimento nas pessoas e na sua qualificação, através de saúde, educação e outros serviços. Esses serviços podem ser custeados pelas receitas tributárias pagas pelas empresas, cujas receitas podem ser acrescidas pelo bom desempenho econômico gerado pelo melhor clima de investimento. É um pensamento em cadeia, em que algumas medidas desencadeariam outras, de forma linear. Em 2006, o BM reafirma sua postura ${ }^{21}$ em seu Relatório Anual.

Em 2011, no Relatório Conflito, Segurança e Desenvolvimento, O Banco Mundial apontou que cerca de 1.5 bilhão de pessoas viviam em locais afetados pela fragilidade, conflitos ou violência criminal. Esse quadro de insegurança coletiva impacta nos vetores de combate à pobreza, prejudicando seus desempenhos.

Apesar de grande parte do mundo ter progredido rapidamente na redução da pobreza nos últimos 60 anos, áreas caracterizadas por repetidos ciclos de violência política e criminal estão sendo deixadas bem atrás, ficando com o crescimento econômico comprometido e indicadores humanos estagnados (BANCO MUNDIAL, 2011, p. 1).

A violência criminal organizada em altos níveis impede o desenvolvimento econômico, e age no sentido de comprometer as possibilidades empreendidas pelo BM, trazendo consigo altas consequências sociais ${ }^{22}$, podendo afetar a economia global, além dos elevados custos para efetivar tentativas para sua contenção. O Banco aponta a dificuldade de elucidar as causas e consequências

\footnotetext{
${ }^{21}$ Os dois pilares da estratégia de combate à pobreza do Banco Mundial são a melhoria do clima de investimento e o empoderamento das pessoas de baixa renda. Esses pilares estão inter-relacionados, pois o progresso no desenvolvimento humano propicia a capacidade para sustentar as melhorias no clima de investimento, apoiar o crescimento econômico e abordar as desigualdades econômicas e sociais (BANCO MUNDIAL, 2006, p. 19).

${ }^{22}$ De acordo com o BM (2011, p. 5), “As pessoas nos Estados frágeis e afetados por conflitos têm mais de duas vezes a probabilidade de estarem subnutridas do que as pessoas em outros países em desenvolvimento, mais de três vezes a probabilidade de serem incapazes de enviar seus filhos à escola, duas vezes a probabilidade de verem seus filhos morrerem antes dos 5 anos de idade, e mais de duas vezes a probabilidade de carecerem de água potável".
} 
da violência, mas associa um baixo PIB per capita a conflitos políticos e altas taxas de homicídios. A falta de emprego entre os jovens é apontada pelas pesquisas desenvolvidas pela instituição como o principal condicionante para o ingresso daqueles em movimentos rebeldes ou gangues urbanas. A estratégia orientada para romper com esses ciclos de insegurança e reduzir sua recorrência é a construção de instituições legítimas capazes de oferecer segurança cidadã, justiça e empregos, ampliando a participação de grupos sociais que poderiam recorrer à violência armada.

No ano de 2013, o Relatório Anual, além de confirmar o combate à pobreza como a essência da missão do Grupo Banco Mundial, lança dois objetivos: reduzir o percentual de pessoas que vivem com menos de U\$1,25 por dia para, no máximo, 3\% até 2030 e; promover o bem-estar e o aumento da renda dos $40 \%$ mais pobres nos países em desenvolvimento, a chamada Prosperidade Compartilhada. A ideia é que o progresso econômico beneficie mais essa parcela da população. Afirma o BM ter ingressado em uma nova era ao adotar medidas mensuráveis para atingir as metas. Diferente do afirmado em 2005, apenas o crescimento econômico não se constitui como a peça chave para alterar os padrões de vida da população pobre.

Para alcançar esses objetivos será necessário reconhecer que apenas o crescimento econômico não construirá o bem-estar sustentado e inclusivo; os níveis mais elevados de distúrbios sociais em todo o mundo são causados, em parte, por um aumento da desigualdade econômica e pela falta de oportunidades inclusivas. $\mathrm{O}$ alcance desses objetivos exigirá maior cooperação entre os parceiros no desenvolvimento, inclusive organizações multilaterais e seus Estados membros. Essa cooperação é essencial em um momento de incerteza econômica global continuada (BANCO MUNDIAL, 2013, p. 7, grifo nosso).

Assim, as estratégias passam a problematizar a questão da desigualdade e seus efeitos sobre a sociedade, gerando entraves para o processo de desenvolvimento. Os esforços se direcionam para a elevação das rendas dos mais pobres no mundo. Traz, portanto, uma relação entre a desigualdade e os índices de pobreza. De acordo com o Relatório (2013), à época, o número de pessoas vivendo na extrema pobreza era de 1,2 bilhão de pessoas, ou $21 \%$ da população do mundo em desenvolvimento. Além disso, a publicação aponta a impossibilidade de se cumprir os Objetivos do Milênio até a data estabelecida (2015); até aquele ano somente 4 metas, das 21 traçadas e englobadas nos 8 objetivos maiores, foram atingidos no mundo todo. O Banco Mundial estabelece com isso uma série de setores necessários para planejar sua intervenção ${ }^{23}$ para melhorar a vida desses $40 \%$ que vivem em países em desenvolvimento.

Mas a desigualdade econômica que é contemplada no Relatório não se remete ao caráter próprio do sistema capitalista, caracterizado pela propriedade privada e exploração e expropriação do trabalho. Não se refere à concentração de renda nas mãos de alguns poucos capitalistas, comprometendo a distribuição da riqueza para o restante da população, como algo inerente a essa sociedade. Aqui, a desigualdade é tratada, primeiramente, pelas suas consequências prejudiciais à coesão social, como uma ameaça à ordem. Segundo, ela é marcada pelo caráter individual, em que é necessário algum investimento no pobre para que ele aumente sua capacidade, aproveite oportunidades, supere a condição de pobreza e passe a ter uma condição social menos desigual.

\footnotetext{
${ }^{23}$ Abordagem dos desafios da mudança climática; Apoio às pessoas em países afetadas por conflitos e frágeis; Investimento em educação e saúde; Promoção de oportunidades para mulheres e meninas; Trabalho para criação de empregos, promoção do comércio e apoio à proteção social; Permitir a participação econômica por meio de inclusão financeira; Investimento em agricultura para segurança alimentar; Transformação de vidas por meio de infraestrutura; Parcerias para gerenciamento de riscos e desastres (BANCO MUNDIAL, 2013).
} 
Na publicação do Banco Mundial chamada La pobreza y la prosperidade compartida 2018: Armando el rompecabezas de la pobreza, de 2018, o presidente do Grupo Banco Mundial, Jim Yong Kim, reafirma o objetivo afirmado em 2013, de reduzir a população que vive na extrema pobreza para menos de 3\% e traz os avanços da luta no combate à pobreza nos últimos 25 anos: se em 1990 um terço da população vivia nessa condição, os últimos dados disponíveis, de 2015, apontam uma queda para 1/10 da população mundial. Segundo consta, "A pobreza não implica apenas uma falta de renda e de consumo: ela também manifesta-se na forma de baixos níveis educacionais, resultados insatisfatórios em saúde e nutrição, falta de acesso a serviços básicos e um ambiente perigoso" (KIM, 2018, p. IV, grifo meu). Ainda diz sobre a importância de conhecer a pobreza em todas as suas manifestações para erradicá-la. Estabelece um "novo conjunto de linhas e medições da pobreza [que] amplia a maneira como concebemos a pobreza" (KIM, 2018, p. IV). Apresenta os resultados da medição da pobreza multidimensional levando em conta os componentes "múltiplos e coincidentes da pobreza" (KIM, 2018, p. IV). Agora, examina a desigualdade intrafamiliar, que pode fazer com que uma pessoa viva na pobreza em lugares que não são pobres.

Ampliando sua perspectiva, sob a justificativa da pobreza multidimensional ser um problema complexo e a possibilidade de identificar os pobres que têm se mantido ocultos, o BM $(2018$, p. 6) incorpora "três novas peças no quebra-cabeças da pobreza", novas formas de medir e conceituar a pobreza, de acordo com a citação:

Nas novas medições se reconhece que as pessoas podem definir-se como pobres em relação à sociedade em que vivem, incluindo quando seus níveis de consumo superam amplamente o nível de U\$1,90. Estas medições também ampliam nosso panorama da pobreza ao incluir elementos de bem-estar básicos, como acesso ao saneamento e serviços básicos de saúde. Por último, nos permitem ir além de lugares em uma primeira intenção de medir a pobreza a nível dos indivíduos (BANCO MUNDIAL, 2018, p. 6).

A defesa nesse enfoque mais amplo sobre a pobreza se assenta no melhor entendimento das diversas dimensões da pobreza a nível mundial, o que pode ser útil para orientar as políticas e identificar as regiões com maiores necessidades. As novas medições também podem ajudar a monitorar os avanços na luta contra a pobreza em um mundo em crescimento, inclusive nos países com baixas taxas de extrema pobreza, visto que o Banco entende que o dinheiro, embora fundamental, não é o único elemento necessário para viver fora da pobreza.

A Linha Internacional da Pobreza (LIP) estabelecida pelo BM é de U\$1,9024 por dia. Entretanto, uma pessoa com uma renda superior a essa pode sentir-se pobre caso não tenha acesso à educação, serviços básicos e atenção de saúde e seguridade, essenciais ao bem-estar. Esse enfoque multidimensional evidencia que a pobreza é um problema mais generalizado e reforça a importância de investimentos em capital humano. Segundo essa definição, que abarca consumo, educação e acesso a serviços básicos, a proporção de pobres aumenta cerca de 50\% em uma comparação somente com a pobreza monetária.

Outro ponto defendido pela instituição para entender como as pessoas sofrem a pobreza, é a necessidade de examinar como são distribuídos os recursos entre os membros de cada família. Além de quadros mais gerais, de gênero e idade - nos países mais pobres, mulheres e crianças tem

\footnotetext{
${ }^{24}$ Valor atualizado em 2015 que estabelece a Linha Internacional da Pobreza (LIP), em substituição ao valor anterior, de U\$ 1,25 ao dia. Esse é o mecanismo fundamental do Banco Mundial para monitorar os avanços sobre a luta empreendida contra a extrema pobreza.
} 
menor acesso a recursos e serviços básicos - estudos apontam uma distribuição não equitativa de bens de grandes valores e mesmo de alimentos dentro das famílias.

O Relatório também traz uma novidade em relação à LIP. A referência de U\$ 1,90/dia para medir a pobreza monetária é utilizada para determinar uma média em que as pessoas possam cobrir suas necessidades básicas nos países mais pobres do mundo. Então surge a importância de considerar linhas de pobrezas mais altas para as pessoas pobres que vivem em países com níveis de renda mais elevado, sendo possível monitorar os avanços de acordo com a satisfação de necessidade em um mundo em crescimento. Foram estabelecidas outras duas linhas, com valores mais altos de U\$ 3,20 e U\$ 5,50 por pessoa ao dia, respectivamente para os países de renda média baixa e os de renda média alta. Se a LIP de U\$3,20 evidencia o resultado dos esforços no combate à pobreza que são ocultos quando de uma análise centrada na extrema pobreza ${ }^{25}$, a LIP de U\$ 5,50 alerta que quase metade da população mundial vive com menos desse valor e, nas regiões do Oriente Médio e Norte da África, Ásia Meridional e África Subsaariana, mesmo com avanços nas taxas de pobreza, o número de pessoas que viviam com menos de U\$ 5,50 era menor em 1990 do que em 2015, devido ao crescimento demográfico.

Sob um olhar mais complexo das necessidades básicas, que podem variar de acordo com o nível de consumo e de renda em cada país, e buscando uma maior compreensão da pobreza, o BM incorpora outra linha de pobreza, a social:

Para avaliar esse tipo de pobreza, o Banco Mundial incorpora a linha de pobreza social (LPS), que segue as convenções das sociedades como complemento das linhas já existentes. A LPS é uma combinação da LIP absoluta e uma linha de pobreza que guarda relação com o nível médio de renda em cada país (BANCO MUNDIAL, 2018, p. 13).

A linha de pobreza social (LSP) retrata as particularidades dos níveis de padrão de consumo de cada sociedade. Sob essa forma de definir a pobreza, o número de pobres que viviam na extrema pobreza no mundo em 2015, data do último levantamento realizado pelo Banco, 736 milhões de pessoas, quase triplica. Os números demostram avanços do Banco no combate à pobreza. Mas quando o entendimento se amplia para além da questão monetária, a falta de acesso a elementos básicos de bem-estar denuncia o quão longe estamos de uma sociedade capaz de prover condições que supram as carências e estabeleçam acesso a direitos fundamentais.

A ideia de pobreza do Banco vai se complexificando e agregando outros elementos para sua consideração. Mas o que podemos dizer é que as investidas do Banco não representam uma alternativa à pobreza, como se essa pudesse ser completamente eliminada. As medidas adotadas são uma forma de administrar as consequências desse modo de produção, institucionalizando uma ligeira ideia de que o sistema se importa com os desdobramentos da sua vigência. Não é o caso problematizar aqui, mas se analisarmos países da África e de algumas regiões da Ásia e América Latina, talvez essa "administração da pobreza” nem seja realizada em níveis humanamente aceitáveis.

\footnotetext{
${ }^{25}$ Tomamos por exemplo o Oriente Médio e o Norte da África. Nessas regiões, a extrema pobreza reduziu apenas $1 \%$ entre 1990 e 2015, de 6\% para 5\%. Levando em conta a LIP de U\$ 3,20 ao dia, os países dessa região, no mesmo período, a redução de pessoa que viviam com essa renda caiu, de 27\% para 16\% (BANCO MUNDIAL, 2018, p. 12).
} 


\section{Considerações finais}

Queremos sinalizar alguns pontos importantes dessa pesquisa a título de conclusão. Para os países em desenvolvimento, o Banco Mundial é responsável pelas orientações para o desenvolvimento econômico e o combate à pobreza. Realiza essa missão respondendo ao movimento global da economia, apostando ora em políticas desenvolvimentistas durante a expansão da acumulação capitalista após a Segunda Guerra, ora em políticas neoliberais, emergentes na década de 1970. As medidas para o enfrentamento à pobreza também se alternam, como evidenciado, a depender da compreensão dos fatores que a originam. A importância desse entendimento por parte do Banco se refere ao seu poder frente as nações e à alta difusão de suas pesquisas e relatórios em diversas instâncias da vida social ${ }^{26}$.

O BM se coloca como uma instituição que exerce grande influência sobre decisões dos governos nos países em desenvolvimento, incidindo mesmo sobre a formulação das políticas sociais públicas e a prestação de serviços à população dessas localidades. Como exposto, o Banco tem a defesa de que é o desenvolvimento econômico a solução para a questão da pobreza mundial, sendo esse o seu foco. Por outro lado, traça recomendações de medidas para o alívio das condições de vida dos sujeitos pobres, mas apenas como algo pontual e focalizado. Todo esse panorama político está enraizado nessa socialidade, mantendo estreita vinculação e funcionalidade com o grande capital.

Farias e Martins (2007, p. 209-210) dizem que o conceito de pobreza do BM determinado por seus pesquisadores é construído sob uma metodologia não esclarecida em seus documentos. $\mathrm{Na}$ concepção dos autores mencionados, o Banco passa a "impressão é que os pobres estariam sob controle da instituição e de que a ausência de desenvolvimento se encontraria”, como roga o ideário neoliberal, na "incapacidade dos pobres ou na incompetência dos governos". Dessa forma, isento de qualquer determinação social, "apenas uma boa gestão do capitalismo" seria o suficiente para se criar o ambiente eficaz para o combate à pobreza. Isso acarreta entendimentos destoantes sobre o assunto.

Em uma crítica a ideia de multidimensionalidade da pobreza, Siqueira (2013) aponta para uma diversidade de fatores que a originam; não só o econômico, mas cultural, moral, ético, espiritual, identitário, cujo enfrentamento se refere a processos culturais, morais, autoajuda, empoderamento ou inclusão pela educação. A pobreza multidimensional (não apenas centrada na renda, como a unidimensional, e mais abrangente que as necessidades básicas, pois considerando acesso à educação, saúde, infraestrutura) leva em conta a situação avaliada pelo sujeito, de sua vivência e percepções; uma perspectiva subjetiva, que retira a centralidade do modo de produção capitalista como seu produtor e coloca a pobreza como categoria derivada de inúmeros outros âmbitos.

Já Salama e Destremau (1999; p. 52), sob outra percepção sobre esse ponto, defendem ser justamente o aspecto subjetivo que faltava na abordagem sobre pobreza, pois não aplicada aos países em desenvolvimento, mas recentemente incorporada pelo BM conforme publicação de 2018. O fator subjetivo procurar definir um patamar de rendimento que permite aos indivíduos não se sentirem pobres, por exemplo, por não conseguir conquistar uma série de bens que outras pessoas conseguem. "O sentimento de ter se tornado pobre ocorre quando o indivíduo não pode

\footnotetext{
${ }^{26}$ Ao incentivar estudos e produzir vasta gama de documentos sobre a pobreza, o Banco Mundial exerce influência em âmbito global. É comum encontrar citações extraídas destes documentos e estudos em diversas publicações governamentais, acadêmicas e jornalísticas (FARIAS e MARTINS, 2007, p. 204).
} 
mais cumprir os compromissos decorrentes da posição ou do lugar ocupados na sociedade, na família, na etnia ou no meio em que vive, e que é rejeitado pelo mesmo". Os indicadores limitam grande parte dessa experiência humana.

O que se pode avaliar são duas compreensões distintas da multidimensionalidade. Uma, de que a multidimensionalidade se trataria das causas da pobreza, agregando outros elementos à questão econômica, não sendo esta contemplada como determinante. Outra, de que, na verdade, a pobreza se expressa de forma multidimensional e não apenas como déficit de renda, mas também em um complexo de relações sociais como pertencimento, relações entre pessoas e o meio, objetivas e subjetivas.

Tendo pouco valor científico a definição de pobreza, e de pobres, por detrás da objetivação conquistada por processos de classificação, quantificação e construção de indicadores, "representa uma construção política, social e classificadora, impregnada de subjetividade e de relatividade, que depende de quem a usa, do contexto no qual esses fatos, representações e aparições ocorrem" (SALAMA e DESTREMAU, 1999, p. 110). Isso é nítido nos Relatórios do Banco ao longo dos anos. Ao tema da pobreza sempre é acrescido algum novo elemento que, de forma miraculosa, seria a chave para entender a origem e a solução para a pobreza. Assim, a maleabilidade do conceito permite sua instrumentalização e manipulação por parte de quem está envolvido em seus estudos. Um terreno fértil para o Banco Mundial que ignora o processo gerador da pobreza e, através dela, se mantém ativo; como a missão do BM se alicerça no combate à pobreza, a existência desta se mostra mais interessante à instituição do que seu fim. Qual seria o papel do Banco se seu elemento vital for extinto e deixar de conferir a ele uma visão humana levantada pela bandeira do compromisso às camadas mais desprovidas da população? Sua extinção seria eminente, decorrente da perda de sua função nuclear.

\section{Referências:}

ANDERSON, Perry. Balanço do Neoliberalismo. In: Gentili, Anderson, Salama (Orgs). Pós-neoliberalismo: as políticas sociais e o Estado democrático. $6^{\circ}$ ed. Rio de Janeiro: Paz e Terra, 1995. p. 9-23.

BANCO MUNDIAL. Relatório sobre o desenvolvimento mundial. Washington: Banco Mundial, 1990.

BANCO MUNDIAL. Relatório sobre o desenvolvimento mundial. Luta contra a pobreza. Washington: Banco Mundial, 2000/2001.

BANCO MUNDIAL. Relatório sobre o desenvolvimento mundial 2005: Um melhor clima de investimento para todos. Washington, DC: Banco Mundial, 2005.

BANCO MUNDIAL. Relatório Anual de 2006 do Banco Mundial. Washington, DC: Banco Mundial, 2006.

BANCO MUNDIAL. Relatório sobre o desenvolvimento Mundial - Visão Geral. Conflito, Segurança e Desenvolvimento. Washington, DC: Banco Mundial, 2011.

BANCO MUNDIAL. Relatório Anual de 2013 do Banco Mundial - Pobreza e Prosperidade. Washington, DC: Banco Mundial, 2013.

BANCO MUNDIAL. La pobreza y la prosperidade compartida: armando rompecabezzas de la pobreza (panorama general). Washington, DC: Grupo Banco Mundial, 2018.

BÓRON, Atílio. A sociedade civil depois do dilúvio neoliberal. In: Gentili, Anderson, Salama (Orgs). Pósneoliberalismo: as políticas sociais e o Estado democrático. $5^{\circ}$ ed. Rio de Janeiro: Paz e Terra, p. 63-118. 
CHOSSUDOVSKY, Michel. A globalização da pobreza. Impactos das reformas do FMI e do Banco Mundial. São Paulo: Moderna, 1999.

FARIAS, Francisco Adjacy e MARTINS, Mônica Dias. O conceito de pobreza do Banco Mundial. Revista do Observatório das Nacionalidades: Tensões Mundiais. Fortaleza, v. 3, n 5, jul./dez. 2007.

HARVEY, D. O neoliberalismo - história e implicações. São Paulo: Edições Loyola, 2008.

LAURELL, A. C. (org.). Estado e políticas sociais no neoliberalismo. $2^{\circ}$ ed. São Paulo: Cortez/Cedec. 1997.

LEHER, Roberto. Crise do capital e questão social. Estudos do Trabalho, revista da RET (Rede de Estudos do Trabalho), ano III, n 6, 2010. Disponível em: <<http://www.estudosdotrabalho. org/4RevistaRET6.pdf>>. Acesso em: 03/09/2018.

MANDEL, Ernest. O Capitalismo Tardio. São Paulo: Abril S.A, 1982.

MARX. K. Introdução [à Crítica da Economia Política]. In: MARX. K. . Introdução à Crítica da Economia Política; Salário, Preço e Lucro; O Rendimento e suas Fonte: a economia vulgar. São Paulo: Abril Cultural, 1982, p. 3-21.

MARX. K. O Capital: Crítica da economia política. Vol. I. Livro Primeiro: O processo de produção do capital. Editado por Friedrich Engels. São Paulo: Abril Cultural. 1984.

MAURIEL, Ana Paula Ornellas. Relações internacionais, política social e combate à pobreza. Revista em Pauta, Rio de Janeiro, n² 23, v. 6, p. 43-67, jul. 2009.

MAURIEL, Ana Paula Ornellas. Desenvolvimento, pobreza e políticas sócias. Revista em Pauta, Rio de Janeiro, n. 31, v. 11, p. 97-117, 1ํㅗㄹ Semestre de 2013.

NETTO, José Paulo. Desigualdade, pobreza e Serviço Social. Revista Em Pauta, Rio de Janeiro, n 19, p. 134-170. 2007.

PEREIRA, João Márcio Mendes. O Banco Mundial e a construção político-intelectual do "combate à pobreza". TOPOI, n² 21, jul./dez. p. 260-282, 2010.

PEREIRA, Potyara Amazoneida P. Necessidades humanas. Subsídios à crítica dos mínimos sociais. $6^{\circ}$ ed. São Paulo: Cortez, 2011.

SALAMA, Pierre. Abertura e pobreza: qual abertura. Revista Políticas Públicas, v. 9, n 1, p. 19-216, jul./dez. 2005.

SALAMA, Pierre e DESTREMAU, Blandine. O tamanho da pobreza. Economia política da distribuição de renda. Rio de Janeiro: Garamond, 1999.

SANTOS JÚNIOR, Raimundo Batista dos. As políticas sociais do Banco Mundial para os países em desenvolvimento. 2010. 281 fls. Tese - (Doutorado em Ciência Política). Universidade Estadual de Campinas, São Paulo, 2010.

SEN, Amartya. Desenvolvimento como liberdade. Tradução de Laura Teixeira Motta. São Paulo: Companhia das Letras, 2000.

SIQUEIRA, Luana. Pobreza e Serviço Social - Diferentes concepções e compromissos políticos. São Paulo: Cortez. 